\title{
O PLURALISMO JURÍDICO E O DIREITO CONSUETUDINÁRIO DAS COMUNIDADES INDÍGENAS FACE AO ORDENAMENTO JURÍDICO BRASILEIRO
}

LEGAL PLURALISM AND CONSULTING LAW OF INDIGENOUS COMMUNITIES FACING BRAZILIAN LEGAL ORDINATION

JULIA THAIS DE ASSIS MORAES ${ }^{1}$

VIVIANNE RIGOLDI ${ }^{2}$

\section{RESUMO}

O presente trabalho visa analisar o direito consuetudinário das comunidades indígenas como resultado do pluralismo jurídico face ao ordenamento brasileiro. O pluralismo jurídico fundamenta-se na ideia de que o Estado Moderno não é o único agente legitimado a realizar o enquadramento legal das diversas formas de relações sociais. Essa perspectiva se contrapõe a doutrina do monismo jurídico, no qual apenas o Estado possui monopólio para a produção de normas jurídicas, reconhecendo a multiplicidade das fontes e das relações de direito no interior de um mesmo sistema jurídico. O direito consuetudinário das comunidades indígenas surge como produto dessa multiplicidade de fontes e relações jurídicas representada pela Constituição Federal de 1988 e as normas infraconstitucionais. Com isso, o objetivo geral da pesquisa é investigar o conceito do pluralismo jurídico, e como objetivo especifico tem-se a análise do direito consuetudinário indígena como um elemento da multiplicidade das relações jurídicas reconhecido pela Constituição Federal de 1988. Ao final, responde-se ao questionamento acerca do direito consuetudinário das comunidades indígenas enquanto expressão do pluralismo jurídico face ao ordenamento legal pátrio. Para tanto, a partir de levantamento bibliográfico e qualitativo, o estudo descritivo e exploratório do tema desenvolveu-se por meio do método hipotético dedutivo de abordagem científica.

1 Mestranda em Teoria Geral do Direito pelo Centro Universitário de Marília UNIVEM 2019/2021, Mestranda em Ciências Sociais pela Universidade Estadual Paulista, UNESP -FFC, Campus de Marília 2019/2021. Graduada em Direito (2014/2018) na Universidade Federal de Mato Grosso do Sul/ UFMS-CPTL. ORCID iD: http://orcid.org/0000-0003-4197-6360. E-mail: juliamoraes094@outlook.com.

2 Doutora em Direito área de concentração Sistema Constitucional de Garantia de Direitos pela Instituição Toledo de EnsinoITE (2017). Mestre em Direito pelo Centro Universitário Eurípides de Marília - UNIVEM (2009). Mestre em Ciências Sociais pela Universidade Estadual Paulista Júlio de Mesquita Filho-UNESP (2002). Especialista em Direito Processual Civil pela Fundação de Ensino Eurípides Soares da Rocha (1999). Graduada em Direito (1994), atualmente é professora titular do Centro Universitário Eurípides de Marília-UNIVEM na Graduação e na Pós Graduação. ORCID iD: http://orcid.org/0000-00029520-9936. E-mail: rigoldi@univem.edu.br. 
PALAVRAS-CHAVE: Pluralismo jurídico. Direito consuetudinário indígena. Comunidades indígenas.Constituição de 1988.

\section{ABSTRACT}

The present work aims to analyze the customary law of the indigenous communities as a result of the legal pluralism in face of the Brazilian order. Legal pluralism is based on the idea that the Modern State is not the only legitimate agent to carry out the legal framework of the various forms of social relations. This perspective is opposed to the doctrine of legal monism, in which only the State has a monopoly for the production of legal norms, recognizing the multiplicity of sources and relations of law within the same legal system. The customary law of indigenous communities appears as a product of this multiplicity of sources and legal relations represented by the Federal Constitution of 1988 and the infraconstitutional rules. With this, the general objective of the research is to investigate the concept of legal pluralism, and as a specific objective we have the analysis of customary indigenous law as an element of the multiplicity of legal relations recognized by the Federal Constitution of 1988. In the end, we answer the questioning about customary law of indigenous communities as an expression of legal pluralism in the face of the national legal system. Therefore, from a bibliographic and qualitative survey, the descriptive and exploratory study of the theme was developed using the hypothetical deductive method of scientific approach.

KEYWORDS: Legal pluralism. Customary indigenous law. Indigenous communities. 1988 Constitution.

\section{INTRODUÇÃO}

O pluralismo jurídico é uma corrente de pensamento que se contrapõe ao Direito Estatal monista, no qual somente o Estado possui o monopólio para elaborar e legitimar normas (WOLKMER, 2001, p.123). Essa oposição ao monopólio estatal ocorre em razão da existente diversidade cultural em todas as sociedades e, assim, a cultura abrange aspectos sociais, mitológicos, religiosos, simbólicos, jurídicos capazes de construírem modos próprios de se expressarem e traduzirem o que está em sua volta (CURI, 2005, p.100).

Diante desse cenário, as comunidades indígenas passam a representar um importante elemento das multiplicidades das fontes e relações jurídicas no ordenamento brasileiro. Ressalte-se que, o último censo do Instituto Brasileiro de Geografia e Estatística, o IBGE, declarou que o Brasil possui 12,5 \% de territórios indígenas no território nacional.

Nesses territórios as comunidades indígenas surgem como elementos expressivos do pluralismo jurídico face ao ordenamento jurídico brasileiro, pois a organização social e os costumes indígenas configuram uma dinâmica social própria e criam um ordenamento jurídico dentro do ordenamento jurídico estatal. A concepção do ordenamento jurídico das regras consuetudinárias indígenas demonstra a coexistência de dois ou mais sistemas normativos em um mesmo espaço, significando que pode haver uma multiplicidade de leis, em decorrência do reconhecimento das diferenças. Destarte, o pluralismo passa a legitimar a diversidade de fontes jurídicas coexistentes em um mesmo ordenamento.

Segundo Rouland (2003, p. 158-159) há duas versões sobre a conceituação de pluralismo jurídico, a primeira é considerada como um conceito fraco, que é aquela que reconhece a existência de mecanismos jurídicos diferentes para tratar de situações idênticas em um mesmo espaço geográfico. A segunda versão é tratada como um conceito forte, que se edi- 
fica sob a existência de diferentes grupos sociais existentes, que vão além do direito estatal, havendo, portanto, várias ordens jurídicas que podem coincidir ou divergir.

Ademais, o pluralismo jurídico tem como objetivo central demonstrar que o Estado Moderno não é o único agente legitimado a garantir o enquadramento legal das diversas novas relações sociais que vão surgindo. Dessa forma, os pluralistas defendem que o pluralismo jurídico não tem a intenção de negar o direito estatal, mas a de legitimar outras formas jurídicas existentes na sociedade.

No tocante aos sistemas jurídicos das comunidades indígenas, a admissão do direito consuetudinário foi adotado pela República Federativa do Brasil por meio do reconhecimento da organização social, costumes e tradições indígenas na Constituição Federal de 1988, mais especificamente no Capítulo VIII, no Estatuto do Índio, bem como na Convenção 169 da Organização Internacional do Trabalho (OIT) ratificada pelo ordenamento pátrio por meio do Decreto $n^{\circ} 5.051$, de 19 de abril de 2004. Sendo assim, o reconhecimento constitucional dos usos, costumes e tradições indígenas, previsto no caput do artigo 231, e em outras normas que constituem o ordenamento legal pátrio, possibilita a expressão de pluralismo jurídico denominado de independente, no qual a organização interna de uma determinada comunidade é regida por leis não estatais, que são os próprios costumes das comunidades indígenas.

A partir desses esclarecimentos iniciais, a presente pesquisa tem como objetivo investigar o conceito do pluralismo jurídico, e como objetivo específico analisar o direito consuetudinário indígena como um elemento da multiplicidade das relações jurídicas reconhecido pela Constituição Federal de 1988, questionando-se: o direito consuetudinário das comunidades indígenas representa um pluralismo jurídico face ao ordenamento legal pátrio?

Para tanto, a partir de levantamento bibliográfico e qualitativo, o estudo descritivo e exploratório do tema desenvolveu-se por meio do método hipotético dedutivo de abordagem científica.

\section{O CONCEITO DE PLURALISMO JURÍDICO}

O conceito de pluralismo jurídico surgiu por meio do diálogo da antropologia com o estudo das leis, proporcionando uma abordagem interdisciplinar denominada de antropologia do direito ou antropologia jurídica. Para Korsbaek e Vivanco (2009), a antropologia do direito é similar à sociologia do direito, pois as duas estudam a lei como um fenômeno inscrito em um marco amplo da sociedade, objetivando identificar o aparecimento da lei como um elemento da dinâmica social da qual faz parte.

Os pontos de referência do pluralismo, dizem respeito ao fato de que a realidade plural levanta uma desigualdade fática, que se manifesta em todos os aspectos da vida cotidiana, mesmo que os valores contidos nas concepções dos diversos grupos existentes estejam concebidos dentro das fronteiras de um mesmo país e relacionados por origens históricas. (KORSBAEK; VIVANCO, 2009, p.156) 
Diante disso, a Sociologia do Direito (SANTOS, 2010, p. 100) tem investigado o pluralismo jurídico e identificou a existência do Direito em diversos locais, como nas zonas rurais, nos bairros urbanos marginais, no desporto, nas igrejas, nas empresas, nas organizações profissionais, sem origem necessariamente na função típica do poder legislativo, mas sim, nascedouro de relações sociais cotidianas e informais. Às normas desse novo Direito, segundo Santos (2010), dá-se o condão de infraestatais, informais, não oficiais e mais ou menos costumeiras. Nesse sentido, a multiplicidade de fontes do Direito se deve à existência de um Direito vivo, que é representado pelas relações sociais, hábitos e costumes.

O ordenamento jurídico pensado como aquele apenas previsto na legislação, na ciência jurídica ou na jurisprudência torna-se um direito arbitrário e fictício (EHRLICH, 1913 apud SÁNCHEZ-CASTAÑEDA, 2006). Entendendo-se que a origem do Direito não é necessariamente um produto apenas do Estado, sua origem estará também nas diferentes relações sociais podendo, ainda, ser tratado como um conjunto de regras que determina a posição e a função dos indivíduos dentro de um grupo social.

De acordo com Bobbio (2007) é possível identificar duas fases do pluralismo jurídico: a primeira fase se refere ao nascimento e desenvolvimento da historicidade jurídica, por meio da Escola Histórica do Direito, que afirma que os direitos emanam direta ou indiretamente da consciência popular. Assim, vários são os ordenamentos nacionais, visto que existem muitas nações, cada qual com seu ordenamento estatal próprio. Essa primeira forma de pluralismo jurídico é caracterizada como estadista.

A segunda fase se refere à etapa institucional que tem como pressuposto a existência de um sistema jurídico onde exista uma instituição, que se traduz em um grupo social organizado. A consequência dessa teoria institucionalista é a fragmentação da ideia universal do Direito e um enriquecimento dos problemas existentes entre os sistemas jurídicos (BOBBIO, 2007, p. 123).

De forma consoante, Woodman (1998) reconheceu a existência de um pluralismo jurídico estatal e de um pluralismo fora das leis estatais. No primeiro caso, haveria instâncias plurais dentro do sistema estatal, como, por exemplo, as diferentes regras e formas de julgamento de acordos comerciais. Nesses acordos, garante-se certa independência no estabelecimento de suas regras, mas, ao mesmo tempo, exige-se uma harmonia com as normas estatais que estariam acima e abrangendo essas transações. Seria uma espécie de pluralismo de controle. A outra forma de pluralismo estaria desvinculada do Estado, chamado de pluralismo independente, na qual a organização interna de uma dada sociedade é regida por leis não estatais, como, por exemplo, os direitos próprios das comunidades indígenas (WOODMAN, 1998, p.145).

\section{O PLURALISMO JURÍDICO E AS COMUNIDADES INDÍGENAS}

Nas comunidades indígenas o pluralismo jurídico é introduzido de um modo singular. $\mathrm{Na}$ sociedade estatal o Estado cria regras para o indivíduo, enquanto nas comunidades indí- 
genas as regras são coletivas, operadas e recriadas mediante a figura do sujeito coletivo (CURI, 2005, p.153). A figura desse coletivo é expressa como um sujeito de direitos e deveres, o que garante a autodeterminação dos povos indígenas como direito do grupo em gerir a sua sociedade e decidir seu próprio destino.

A partir dessa perspectiva um limite de interferência ao direito impositivo e centralizador do Estado é imposto. Desse modo, o Estado assume um papel de mediador de conflitos e interesses, não mais um papel de interventor. A autonomia do sujeito coletivo deve ser respeitada em termos políticos, administrativos, econômicos, culturais e judiciais, tanto no âmbito interno, como externo à comunidade indígena.

Nesse sentido a autonomia implica (KORSBAEK; VIVANCO, 2009, p.67): na possibilidade de decidir sobre os assuntos que afetam a sua comunidade, sem interferência e/ou pressão de mecanismos legais externos; na participação plena nos órgãos democráticos da Nação; no manejo e administração dos recursos dispostos em suas terras, conforme os seus próprios sistemas normativos e no reconhecimento da sociedade envolvente do seu território em sentido cosmogônico e material .

Essa autonomia das comunidades indígenas que, como visto, implica no direito à sua autodeterminação, diversas vezes entra em conflito com o sistema positivo vigente e as normas próprias das comunidades indígenas. Nesse contexto, o posicionamento estatal pode relativizar a autonomia dos povos indígenas ao estabelecer normas a partir dos sistemas de valores próprios dos representantes do poder legislativo nacional. Os conflitos ocorrem com maior frequência no âmbito do direito penal, em casos tipificados pelo direito estatal como crimes contra a vida, pois estes se fundamentam em um conjunto de valores considerado acima de qualquer outro interesse (CURI, 2005, p. 157).

Isto porque, o sistema jurídico ocidental fundamenta-se na dignidade humana, o que coloca a vida digna, de conceito cultural subjetivo, como um valor universal, legitimando uma ação ostensiva do Estado para coibir o que ele próprio define como ato ilícito contra a vida. A partir disso, o Estado compromete a promoção do justo tratamento que deve ser dispensado no processo penal aos indígenas, seus familiares e, por vezes, às suas comunidades, pois desconsidera sua cultura, organização social e sistema de valores (YAMADA; BELLOQUE, 2010, p.87).

Destaca-se que apesar do ordenamento jurídico brasileiro reconhecer a organização social das comunidades indígenas, a intervenção do Direito estatal nas comunidades não está adequadamente definida. Se por um lado a legislação definida pelo Estado deve ser aplicada em todo o território nacional, por outro, o mesmo Direito estatal garante aos grupos etnicamente diferenciados o direito de viver segundo seus usos e costumes, o que inclui o direito coletivo de definir suas normas internas. Em relação aos povos indígenas, essa perspectiva geral da legislação e, ao mesmo tempo particular, está clara no artigo $1^{\circ}$, parágrafo único do Estatuto do Índio, que estabelece que aos índios e às suas comunidades se estende a proteção das leis do país, resguardados seus usos, costumes e tradições (LEl 6001/1973, BRASIL).

Destaca-se também a Convenção 169 da OIT, ratificada pelo Estado brasileiro, no artigo $9^{\circ}$ (CONVENÇÃO 169 DA OIT, BRASIL), que estabelece o seguinte: 
1.Desde que compatíveis com o sistema jurídico nacional e com os direitos humanos internacionalmente reconhecidos, deverão ser respeitados os métodos a que tradicionalmente recorrem esses povos para a repressão dos delitos cometidos por seus membros.

2.As autoridades e tribunais chamados a se pronunciar sobre questões penais deverão levar em consideração os costumes desses povos sobre a matéria (CONVENÇÃO 169 DA OIT, BRASIL)

A Convenção $n^{\circ} 169$ da OIT garante o respeito às leis internas para impedir crimes cometidos por povos indígenas e coloca os sistemas jurídicos nacionais e os direitos humanos reconhecidos internacionalmente acima dos direitos culturais. 0 direito coletivo deve ser observado, mas não deve entrar em conflito com o sistema de valores da sociedade dominante. Isso significa que a legislação atual reconhece a diversidade cultural, mas também continua a assumir valores etnocêntricos, indicando que a realização do pluralismo jurídico ainda está em construção, podendo gerar pode interpretações suspeitas e erros de julgamento em relação aos direitos indígenas (CURI, 2005, p.160).

\section{O DIREITO CONSUETUDINÁRIO}

O direito consuetudinário é definido como um conjunto de normas sociais tradicionais, criadas espontaneamente por um povo; não são escritas e não são codificadas. 0 termo "consuetudinário" consiste em algo fundado nos costumes, sendo uma espécie de direito costumeiro. 0 direito consuetudinário é diferenciado do direito positivo, em virtude desse último ser fundamentado por uma autoridade política constituída, o Estado, do qual emana todo poder. Enquanto direito costumeiro vigora e opera independentemente da existência dessa autoridade (CURI, 2005, p. 140).

Ressalte-se que, segundo Manuela Carneiro da Cunha (1990), o direito costumeiro só existe em relação ao direito positivo e, portanto, não há como se pensar na sua anterioridade ou autonomia perante o Estado. 0 direito costumeiro, nesse aspecto, só existe em oposição ao direito positivo e seu próprio conteúdo é, parcialmente ou por contraste, informado pela presença do Estado.

Os costumes representam fontes importantes do Direito, uma vez que grande parte das normas se estruturam a partir dos modos de viver de uma sociedade. Por outro lado, o direito positivo vigente fornece aos costumes um valor secundário, colocando o direito costumeiro como algo inferior ou atrasado, como se fosse um estágio anterior à constituição do direito positivo normativo emanado pelo Estado (CURI, 2005, p.141). Essa concepção deriva de teses evolucionistas, que fundamentam suas teorias na ideia de que toda a humanidade atravessa sucessivamente, seguindo uma única direção, uma trajetória do simples para o complexo, do irracional para o racional, compreendendo três fases de desenvolvimento: a selvageria, a barbárie e, finalmente, a civilização.

A ideia da sociedade dominante, que converte a sua cultura em paradigma universal, é a de que esses povos denominados "primitivos" não possuem um sistema de leis, pois a ausência de Estado e de normas escritas demonstra o atraso e o caráter simplificado de sua 
estrutura social. Nos dizeres generalizados dessa sociedade, os povos indígenas não possuem direito, arte ou religião, mas, no máximo, costumes, artesanato e superstições (WOLFF, 2004 , p. 230 )

No mesmo sentido, a doutrina jurídica tradicional é unânime em considerar que o direito codificado proporciona mais certeza ao Direito que as normas costumeiras, sendo justamente esse o motivo que coloca a lei em superioridade sobre o costume, afirmando-se ainda que, com a evolução das sociedades, estas deixam a forma consuetudinária e se transformam, progressivamente, em direito codificado (NADER, 1988, p.124 ).

\section{O DIREITO CONSUETUDINÁRIO DAS COMUNIDADES INDÍGENAS}

A afirmação de que os indígenas não possuem leis ainda é bastante difundida no meio jurídico, sendo que esse posicionamento é comum diante do senso comum e de juristas mais conservadores (CURI, 2005, p.147). Essa compreensão tem origem a partir de uma suposta "primitividade" das relações sociais das comunidades indígenas. Diante dessa postura esses conservadores afirmariam que as comunidades tradicionais não comportariam as características do Direito. Contudo, esse consenso se fundamentava na corrente antropológica evolucionista, que considerava os indígenas um estágio primitivo da evolução social (CURI, 2005, p.150).

A referida concepção evolucionista tornou-se ultrapassada dentro da antropologia jurídica moderna, devido os estudos que demonstraram que cada sociedade possui uma organização, não sendo isso critério de superioridade ou inferioridade na evolução social. Nesse sentido, Davis (1973), observa que "em toda sociedade existe um corpo de categorias culturais, de regras ou códigos que definem os direitos e deveres legais entre as pessoas; em toda sociedade surgem disputas e conflitos quando essas regras são rompidas e, para resolver essas divergências, existem meios institucionalizados mediante os quais as regras jurídicas são reafirmadas e/ou redefinidas" (DAVIS, 1973, p.10).

O direito indígena para ser caracterizado como um direito consuetudinário ou costumeiro, possui os seguintes traços específicos: encontra-se imerso em um corpo social vinculado com todos os outros aspectos da cultura, formando uma unidade; e seu fundamento é extraído da força e da tradição comunitária, que é expressada nos usos e costumes. 0 direito costumeiro para as comunidades indígenas atende a uma cosmovisão fundada em princípios ancestrais que está relacionada com a ordem natural dos acontecimentos (CUEVAS GAYOSSO,2000, p.111).

As regras passam a ser aceitas e aplicadas pela sociedade indígena, em razão de uma consciência coletiva que diz que essas são boas para os homens. As aplicações dessas regras não exigem sua inclusão em textos normativos, pois o que as legitimam é a consciência comum do grupo que, por meio do conhecimento dos princípios gerais que regem as suas condutas, sustentam as regras determinadas para a resolução de problemas específicos (CURI, 2005, p.148). A partir disso é possível ver a diferença entre o direito costumeiro e do 
direito positivo das sociedades modernas, que é a ausência da separação do aspecto social do aspecto jurídico.

O direito para as comunidades indígenas atua submerso no corpo social, nos usos e costumes comunitários, envolvendo tradição oral, sistemas de cargos, fundamentos mágico-religiosos que constituem a cosmovisão particular da comunidade. E em contrapartida as sociedades modernas separam esses dois aspectos, o social e o jurídico, criando uma dicotomia entre a forma e o conteúdo. Nas comunidades indígenas, o direito costumeiro é uma regra de organização comunitária fundada na visão cosmológica, sendo que isso possibilita a flexibilidade e profundidade do direito consuetudinário indígena (CUEVAS GAYOSSO,2000, p.112).

O termo utilizado para conceber o direito consuetudinário é "regra", entendendo-se que não há nele a mesma rigidez do termo "norma jurídica", empregado para o direito positivo. O primeiro possibilita uma adaptação dentro da sociedade em que se manifesta, à medida que o segundo, inserido em um contexto diverso, é rígido e sua aplicação corresponde à imposição da referida norma de conduta aos fenômenos sociais. As regras passam a que se adequar às características da sociedade, convertendo-se em uma expressão comum de um grupo determinado e com tendência em resguardar seus valores e princípios essenciais. Nessa perspectiva, Cuevas Gayosso (2000) ressalta a origem fundamental das regras costumeiras, aquela que denomina "visão cosmológica".

A visão cosmológica é responsável por criar as diversas fontes do direito consuetudinário das comunidades indígenas. Nessa o que cria o Direito não é a vontade do legislador responsável, mas as práticas cotidianas relacionadas à cosmovisão de diversos grupos sociais, que resultam nas criações de regras costumeiras que informalmente tornam-se legítimas para disciplinar o convívio social. Assim, também integra o direito costumeiro, que apesar de não ser escrito, e nem codificado vigora sem a presença do Estado (CURI, 2005, p.140).

\section{O RECONHECIMENTO DO DIREITO CONSUETUDINÁRIO DAS COMUNIDADES INDÍGENAS PELO ORDENAMENTO JURÍDICO BRASILEIRO}

Os capítulos anteriores versaram sobre o conceito do pluralismo jurídico e acerca do direito consuetudinário das comunidades indígenas. Dessa forma, o presente capítulo visa analisar o reconhecimento do direito consuetudinário pelo ordenamento jurídico brasileiro representado pela Constituição Federal de 1988, e de modo infraconstitucional pelo Estatuto do Índio, a Lei $6001 / 1973$. O reconhecimento do direito consuetudinário dos indígenas é dado pelo artigo 231 da Constituição de 1988, que reconhece os índios em conformidade a organização social, costumes, línguas, crenças e tradições.

A Constituição Federal de 1988 inaugurou a constitucionalização dos direitos indígenas, rompendo com o paradigma assimilacionista ou integracionista, que reconheciam os indígenas de acordo com seus usos, costumes e tradições. O não reconhecimento da identidade étnica dos indígenas nas Constituições anteriores, fazia o Estado concebê-los como 
uma realidade transitória, que iria desaparecer à medida que fossem integrados a comunhão nacional. Destaca-se que o fundamento dos textos constitucionais pretéritos era de que os indígenas representavam um estágio primitivo da evolução da sociedade, portanto caberia a sociedade nacional que estava mais a frente na escala evolutiva retirá-los do estágio primitivo (CUNHA, 1992, p.67).

Esse argumento é oriundo do evolucionismo, uma corrente antropológica que nasceu no XVIII, e nesse momento projetava os indígenas como o "Bom Selvagem, sendo eles os testemunhos do paraíso perdido e como a imagem do que teriam sido os ocidentais em tempos passados (ROULLAND, 2000, p. 76). No século XIX, iniciou-se a segunda grande fase das colonizações ocidentais, na qual os conceitos evolucionistas se tornaram mais endurecidos, criando-se a ideia de que a colonização seria um bem aos povos denominados primitivos, pois os ajudariam a sair de sua lentidão evolutiva (KAPLAN, 1975, p. 167).

A primeira fase conhecida como evolucionismo unilinear, sendo que foi essa que exerceu uma forte influência nas constituições brasileiras em relação ao tratamento normativo dado aos indígenas até a Constituição de 1988. Nessa perspectiva, as sociedades tradicionais viviam em um estado atrasado do desenvolvimento da humanidade, estariam na infância das sociedades ditas civilizadas, a comunhão nacional. Diante disso, os diplomas constitucionais consideravam os indígenas como uma realidade transitória, que seriam incorporados à sociedade nacional, o estágio mais avançado da evolução social, deixando para trás seus usos, costumes e tradições (CURI, 2005. p. 27).

Com o reconhecimento dos direitos indígenas, como seus usos, costumes e tradições o texto constitucional rompeu com o evolucionismo, que justificava o assimilacionismo e passou a reconhecer os indígenas de acordo com sua identidade étnica. Em todo o texto constitucional há o reconhecimento de direitos indígenas, contudo o capítulo VIII - Dos Índios demonstra da forma mais sensível o reconhecimento estatal. Desse modo, no artigo 231 é possível extrair vários direitos em relação os indígenas, o mais evidente é o direito as terras originárias, mas o reconhecimento dos usos, costumes e tradições na primeira parte do referido artigo traz o direito à autodeterminação e o direito a alteridade, bem como o reconhecimento do direito consuetudinário das comunidades indígenas.

0 direito consuetudinário não está expresso no texto do caput do artigo 231, como o direito à autodeterminação e o direito a alteridade, que é o direito dos indígenas viverem de acordo com os seus usos costumes e tradições, e exercê-los (BRASIL, 1988). Entretanto, o respeito aos direitos internos (ou costumeiros) das comunidades indígenas é afirmado de forma intrínseca, pois não há como reconhecer aos índios suas organizações sociais sem reconhecer seus sistemas jurídicos próprios

O Estatuto do Índio, a lei 6001/1973 é anterior Constituição Federal de 1988, portanto sua política normativa foi concebida sob a égide do evolucionismo unilinear que considerava os indígenas como inferiores a comunhão nacional, e deveriam ser incorporados a sociedade mais avançada. Com isso o estatuto carregava a contradição de proteger e ao mesmo tempo incorpora-los. A Constituição de 1988 adotou uma postura diversa a do Estatuto Índio, reconhecendo os direitos indígenas, assim todos os dispositivos que visavam a assimilação dos indígenas à comunhão nacional foram revogados (LIMA, 2016, p.100). Contudo, os artigos que visavam a proteção dos direitos indígenas continuaram vigentes, tal como a proteção aos direitos costumeiros dos indígenas: 
Cumpre à União, aos Estados e aos Municípios (...), para a preservação das comunidades indígenas e a preservação dos seus direitos: respeitar (...) as peculiaridades inerentes a sua condição; assegurar aos índios a possibilidade de livre escolha dos seus meios de vida e subsistência; respeitar (...) a coesão das comunidades indígenas, os seus valores culturais, tradições, usos e costumes (art. $2^{\circ}$, incisos III, IV e V). (LEI 6001/1973, BRASIL )

\section{A CONVENÇÃO 169 DA OIT E O RECONHECIMENTO INTERNACIONAL DO DIREITO CONSUETUDINÁRIO DAS COMUNIDADES TRADICIONAIS}

A Convenção 169 da OIT torna-se importante nesse contexto do pluralismo jurídico e o reconhecimento do direito consuetudinário das comunidades indígenas pelo ordenamento brasileiro, uma vez que a República Federativa do Brasil a ratificou por meio do decreto $\mathrm{n}^{\circ}$ 5.051, de abril de 2004. A referida convenção, assim como a Constituição de 1988 legitimou o direito dos indígenas de viverem segundo seus usos e costumes. Assim, também foi reconhecido que os indígenas e suas organizações tradicionais deveriam estar envolvidas no planejamento e execução dos projetos de desenvolvimento que os afetassem.

Isso se constitui a partir dos princípios de respeito às culturas, às formas de vida e ao direito consuetudinário dessas comunidades ( CONVENÇÃO 169 DA OIT , BRASIL ).Dentre os mecanismos de legitimação dos direitos indígenas adotados pela convenção dois pontos fundamentais são constantemente evocados para garanti-los : a necessidade de consulta às comunidades indígenas, mediante procedimentos apropriados, quando medidas legislativas ou administrativas possam afetá-los diretamente; e o direito de definir seu desenvolvimento de acordo com as suas aspirações e modos próprios de vida, ou seja, o direito de escolher suas prioridades e promover o seu próprio desenvolvimento econômico, social e cultural (CONVENÇÃO 169 DA OIT , BRASIL )

Em relação aos direitos consuetudinários dos povos indígenas, a Convenção 169 da OIT, em seu artigo $8^{\circ}$, determina:

Ao aplicar a legislação nacional aos povos interessados, dar-se-á a devida consideração aos seus costumes ou seu direito consuetudinário.

Esses povos deverão ter o direito de conservar seus costumes e instituições próprias, desde que eles não sejam incompatíveis com os direitos fundamentais definidos pelo sistema jurídico nacional nem com os direitos humanos internacionalmente reconhecidos. Sempre que for necessário, deverão ser estabelecidos procedimentos para se solucionar os conflitos que possam surgir na aplicação deste princípio (CONVENÇÃO 169 DA OIT, BRASIL).

Diante do dispositivo, constata-se que os direitos internos dos povos indígenas, chamados pelo direito positivo de direito consuetudinário, é reconhecido tanto pelo ordenamento internacional, quanto pelo ordenamento brasileiro. No entanto, esse reconhecimento é com ressalvas, o direito consuetudinário dos indígenas não pode ser incompatível com os direitos fundamentais dos Estados e com os direitos humanos internacionais. Sendo que isso será analisado no capítulo seguinte. 


\section{O CONFLITO DE NORMAS DO DIREITO}

\section{POSITIVO COM O DIREITO CONSUETUDINÁRIO DAS COMUNIDADES INDÍGENAS}

O ordenamento brasileiro é fundado sob um Estado Democrático de Direito, e tem como princípio fundamental a dignidade da pessoa humana. Nesse sentido, o princípio da dignidade humana serve de fundamento a todo o ordenamento jurídico, podendo ser encontrada em todo texto constitucional. A dignidade da pessoa humana é elencada como um dos fundamentos da República Federativa do Brasil , no artigo $1^{\circ}$, III ,mas também em outras partes do texto constitucional, como no art. 170, caput, que diz que "a ordem econômica, fundada na valorização do trabalho humano e na livre iniciativa, tem por finalidade assegurar a existência digna, conforme os ditames da justiça social". No artigo $226 \S 7^{\circ}$ expressa que o planejamento familiar deve ser fundado nos princípios da dignidade da pessoa humana e da paternidade responsável (BRASIL, 1988).

A dignidade humana pode ser reconhecida por dois elementos: o valor intrínseco de todos os seres humanos e a autonomia de cada indivíduo; sendo que a autonomia pode ser limitada por algumas restrições em nome de valores sociais ou interesses estatais e pelo valor comunitário (BARROSO, 2013, p.72). O valor intrínseco representa as características próprias dos seres humanos, uma vez que isso os diferencia de outras espécies. Essa característica também origina vários direitos fundamentais garantidos no direito, sendo o principal deles o direito à vida. A autonomia, é o direito do indivíduo de fazer as suas próprias escolhas, que no campo jurídico é pautado pela autonomia privada e autonomia pública. 0 valor comunitário representa o papel do Estado no estabelecimento de metas a serem cumpridas de forma coletiva, bem como, as restrições impostas aos indivíduos em nome de um bem maior (BARROSO, 2013 ,p. 73 ).

Os três elementos conceituados tornam-se importantes para compreender um eventual conflito de normas dos direito positivo e do direito consuetudinário das comunidades tradicionais. Como foi demonstrado nos capítulos anteriores a Constituição Federal de 1988 reconheceu os direitos indígenas, inaugurando a constitucionalização dos direitos tradicionais (BARBIERI, 2009, p. 69), ainda que o direito consuetudinário não tenha sido mencionado ipsis literis é possivel inferi-lo em razão do reconhecimento dos usos, costumes e tradições dados aos indígenas no caput do artigo 231 . Nesse sentido, quando o direito consuetudinário não violar a dignidade humana, ou seja não violar o direito a vida e nem colaca-lo em risco, pode-se inferir que o ordenamento jurídico positivo vai reconhecê-lo, visto que esse compõe a identidade indígena e é reconhecido pelo texto constitucional .

O reconhecimento do direito consuetudinário dos indígenas pelo ordenamento positivo brasileiro, quando esse não violar a dignidade humana (o direito a vida ) representa de fato a consolidação de um Estado Democrático de Direito. Sendo que essa consolidação se realiza na conjugação de uma concepção de uma sociedade pluralista, livre, justa, fraterna e solidária (SILVA, 2016, p. 345 ), que reconhece e protege as diferenças sociais existentes em uma sociedade diversificada como a sociedade brasileira. Com isso, torna-se necessário destacar a noção de dignidade humana em aspecto negativo, pois essa auxilia a compreensão de considerar o direito consuetudinário das comunidades tradicionais. 
No aspecto negativo significa que cada integrante da sociedade precisa ser respeitado e estimado pelo Estado e pelos outros membros da sociedade em sua grandeza individual, sem nenhuma probabilidade de rebaixamento, exploração, discriminação, exclusão, ou tratamento inumano. Nesse sentido, e no contexto do direito consuetudinário das comunidades tradicionais, pode-se compreender que o corpo jurídico da organização social dos indígenas irá prevalecer quando respeitar o ser humano , e sua dignidade, visto que esse compõe a sua grandeza individual. Portanto, lei positiva poderá considera-lo uma vez que esse direito consuetudinário integra a identidade étnica indígena.

\section{CONCLUSÃO}

O pluralismo jurídico como foi analisado não admite apenas o Estado como detentor do monopólio de elaborar e legitimar normas. Essa oposição se dá devido a existência da diversidade cultural inerente a qualquer sociedade, e essa diversidade cultural envolve aspectos sociais, mitológicos, religiosos, simbólicos, e jurídicos aptos a construírem modos próprios de se expressarem e traduzirem o que está em sua volta. Assim, as comunidades tradicionais representam um importante elemento das multiplicidades das fontes e relações jurídicas face ao ordenamento brasileiro. Uma vez que o reconhecimento das comunidades indígenas e sua organização social foi legitimada pela Constituição Federal de 1988, que dedicou o capítulo VIII especificamente aos direitos indígenas.

O texto constitucional ao reconhecer a organização social das comunidades indígenas admite o direito consuetudinário, configurado na existência de um efetivo pluralismo jurídico. Dessa forma, as comunidades indígenas são regidas por regras coletivas, as quais são respeitadas, recriadas na figura do sujeito coletivo e admitidas pelo sistema brasileiro positivo na medida do respeito à dignidade humana dos envolvidos. A diferença crucial entre o direito consuetudinário e o positivo é que esse dita cria regras para o indivíduo, enquanto as comunidades indígenas ditam regras comunitárias. Sendo que essa figura coletiva de "comunidade " é projetada como um sujeito de direitos, que proporciona o direito à autodeterminação dos indígenas se regerem conforme suas regras.

Com isso o Estado brasileiro assume o papel de mediador de eventuais conflitos e interesses do direito consuetudinário indígena, quando esse colidir com a dignidade humana, e intervir com seu direito positivo apenas quando for para proteger o direito à vida. Quando o direito consuetudinário das comunidades indígenas não ameaçar a vida, bem como a dignidade humana, pode-se afirmar que esse irá prevalecer, uma vez que o Estatuto do Índio já previa essa proteção tal como o texto constitucional. No referido estatuto é claro que cumpre aos entes federativos respeitar suas peculiaridades inerentes a sua condição; bem como assegurar aos índios a possibilidade de livre escolha dos seus meios de vida e subsistência e respeitar a coesão comunitária inerente aos seus valores culturais, tradições, usos e costumes.

A admissão do direito comunitário pelo ordenamento brasileiro foi mais uma vez reafirmada com a ratificação da Convenção 169 da OIT. Documento internacional que reconheceu os direitos humanos indígenas em âmbito internacional, sendo um desses o direito consue- 
tudinário dos indígenas. Segundo a convenção os direitos consuetudinários das comunidades tradicionais devem sempre ser considerado, uma vez que esse compõe a organização social tradicional. 0 direito costumeiro dos indígenas, que envolvem seus costumes e instituições deve ser respeitado quando compatíveis com os direitos fundamentais e direitos humanos que se fundamentam sob a proteção da dignidade humana. E quando houver um eventual conflito entre a norma de direito positivo e a regra de direito consuetudinário deve-se levar em consideração aquela que mais protege a vida e a dignidade humana.

Ademais, a Constituição Federal de 1988 ao reconhecer os direitos indígenas rompeu com o paradigma assimilacionista que orientava os textos constitucionais anteriores, fundamentando-se na dignidade da pessoa humana que é um dos pilares do Estado Democrático de Direito. Assim, esse princípio basilar do Estado brasileiro é ratificado como um de seus fundamentos, o que possibilita a existência de um pluralismo jurídico; de um lado tem-se o ordenamento positivo e, do outro, o ordenamento das regras consuetudinárias das comunidades tradicionais. Nesse sentido, os direitos consuetudinários das comunidades tradicionais coexistem face o ordenamento positivo do estado brasileiro quando se mostrarem compatíveis a dignidade humana e a vida.

\section{REFERÊNCIAS}

BARBIERI, S. R. J.Os Direitos Constitucionais dos Índios e o direito a diferença, face ao princípio da dignidade da pessoa humana. Coimbra: Almedina, 2008.

BARROSO, Luís Roberto. A Dignidade da Pessoa Humana no Direito Constitucional Contemporâneo: A Construção de um Conceito Jurídico à Luz da Jurisprudência Mundial.. Belo Horizonte: Fórum, 2013.

BOBBIO, Norberto. O Positivismo Jurídico: Lições de Filosofia do Direito. São Paulo: Ícone, 1995.

BOBBIO, Norberto. Teoria Geral do Direito. São Paulo: Martins Fontes, 2007.

BRASIL. Constituição da República Federativa do Brasil de 1988. Disponível em

http://www.planalto.gov.br/ccivil_03/constituicao/constituicao.htm. Acesso em 15 abr. 2020.

BRASIL. Estatuto do Índio Lei 6001/1973. Disponível em: http://www.planalto.gov.br/ccivil_03/leis/L6001.htm. Acesso em 15 abr. 2020.

BRASIL. Decreto 5.051, de 19 de abril de 2004. Dispõe sobre a Convenção nº 169 da

Organização Internacional do Trabalho-OIT sobre Povos Indígenas Tribais. Disponível em:

http://www.planalto.gov.br/ccivil_03/_ato2004-2006/2004/decreto/d5051.htm. Acesso em 15 jul. 2017.

CUEVAS GAYOSSO, José Luis. La Costumbre Jurídica de los Pueblos Indígenas en la Constitución Del Estado de Vera Cruz, México (2000), de la Norma a la Práxis. México: Revista de la Facultad de Derecho de la Universidad Veracruzana, Universidad Veracruzana, 2000.

CUNHA, Manuela Carneiro da. El Concepto de Derecho Consuetudinário y los Derechos Indígenas en la Nueva Constituicion de Brasil. In: Entre la Ley y la Costumbre: el derecho consuetudinário indígena en América Latina, Instituto Indigenista Interamericano e Instituto Interamericano de Derechos Humanos, México, 1990.

CUNHA, Manuela Carneiro da. História dos Índios no Brasil. São Paulo: Companhia das Letras: Secretaria Municipal de Cultura: FAPESP, 1992.

CURI, Melissa V. Mineração em Terras Indígenas: Caso Terra Indígena Roosevelt. Dissertação de Mestrado, Universidade Estadual de Campinas, Instituto de Geociências, Campinas, 2005. 
CUNHA, Manuela Carneiro da. O Direito Consuetudinário Dos Povos Indígenas E O Pluralismo Jurídico. Espaço Ameríndio (UFRGS), 2012.

CUNHA, Manuela Carneiro da. Antropologia Jurídica: um estudo do direito Kamiurá. Crítica Jurídica, 2005.

DAVIS, Shelton. Antropologia do Direito - Estudo Comparativo de Categorias de Dívidas e Contratos. Rio de Janeiro: Zahar Editores, 1973.

KAPLAN, David e MANNERS, Robert A. Teoria da Cultura. Tradução de Zilda Kacelnik, Rio de Janeiro: Zahar Editores, 1975.

KORSBAEK, Leif e VIVANCO, Florecia Mercado. La Sociedad Plural y el Pluralismo Jurídico, un Acercamiento desde la Antropologia del Derecho. Disponível em: http://www.bibliojuridica.org/libros/4/1670/10.pdf. Acesso em 29 abr. 2020.

NADER, Paulo. Introdução ao Estudo do Direito. Rio de Janeiro: Forense, 1993.

ROULAND, Norbert. Nos Confins do Direito. São Paulo: Martins Fontes, 2003.

SANTOS, Ricardo Ventura e COIMBRA JR., Carlos E. A. Parece feito por um molde único: cultura, sociedade e bioantropologia no Alto Xingu. In: FRANCHETTO, Bruna e HECKENBERGER, Michael (Orgs). Os Povos do Alto Xingu: história e cultura. Rio de Janeiro: Editora UFRJ, 2001.

SANTOS FILHO, Roberto Lemos dos. Apontamentos sobre o Direito Indigenista. $1^{\text {a }}$ edição, Curitiba: Juruá, 2006. SILVA, José Afonso. Teoria do Direito Constitucional, 15ª Ed. Saraiva, São Paulo.

WOLFF, Francis. Quem é Bárbaro? In: Civilização e Barbárie. Org. Adauto Novaes, São Paulo: Companhia das Letras, 2004.

WOLKMER, Antônio Carlos. Pluralismo Jurídico: fundamentos para uma nova cultura no Direito. São Paulo: Editora Alfa Omega, 2001.

WOODMAN, Gordon R. Ideological Combat and Social Observation - Recent Debate about Legal Pluralism. Journal of Legal Pluralism, nr. 42, 1998.

YAMADA, Erika M. e BELLOQUE, Juliana G. Pluralismo Jurídico: Direito Penal, Direito Indígena e Direitos Humanos - Uma análise do art. 121 do Código Penal brasileiro. In: VILLARES, Luiz Fernando (Coord.). Direito Penal e Povos Indígenas. Curitiba: Juruá, 2010.

Recebido/Received: 11.05.2020.

Aprovado/Approved: 01.09.2020. 